\title{
Clinical Evaluation of New Biomarkers including IFN $-\gamma$ for the Diagnosis of Active Tuberculosis Disease
}

\author{
Yoshihiro Kobashi*, Keiji Mouri, Shigeki Kato, Mikio Oka \\ Department of Respiratory Medicine, Kawasaki Medical School, Kurashiki, Japan \\ Email: "yoshihiro@med.kawasaki-m.ac.jp
}

Received 17 October 2015; accepted 29 November 2015; published 3 December 2015

Copyright (c) 2015 by authors and Scientific Research Publishing Inc.

This work is licensed under the Creative Commons Attribution International License (CC BY). http://creativecommons.org/licenses/by/4.0/

(c) (7) Open Access

\begin{abstract}
Background: The aim of this study was to evaluate the clinical potential of new biomarkers such as IL-2, TNF- $\alpha$, MCP-1, MIP-1 $\beta$ including IFN- $\gamma$ for the diagnosis of active tuberculosis (TB) disease. Materials and Methods: The subjects consisted of 31 patients with active TB disease and 62 patients with non-TB disease. We measured IFN- $\gamma$ using QuantiFERON-TB Gold In Tube, and IL-2, TNF- $\alpha$, MCP-1, and MIP-1 $\beta$ using the supernatant from whole blood stimulated with MTB (Mycobacterium tuberculosis)-specific antigens. Results: In the patient group with active TB disease, while the positive response rate of IFN- $\gamma$ was $74 \%$, that of IL-2 using the supernatant was $61 \%$, TNF- $\alpha$ was $71 \%$, MCP- 1 was $81 \%$ and MIP- $1 \beta$ was $81 \%$. In the patient group with non-TB disease, while the positive response rate of IFN- $\gamma$ was $11 \%$, that of IL-2using the supernatant was $32 \%$, TNF- $\alpha$ was $26 \%$, MCP-1 was $23 \%$ and MIP-1 $\beta$ was $19 \%$. All biomarker levels of the patients with active TB disease using the supernatant were significantly higher than those of the patients with non-TB disease. While MIP-1 $\beta$ was the most sensitive of all the biomarkers (sensitivity: $80.6 \%$ ), IFN- $\gamma$ was the best in terms of specificity (specificity: 87.0\%). Conclusions: Several biomarkers, apart from IL-2, showed similar results compared to IFN- $\gamma$. The combination of IFN- $\gamma$ and other new biomarkers may increase the diagnostic accuracy of active TB.
\end{abstract}

\section{Keywords}

Mycobacterium tuberculosis (MTB) Disease, Interferon- $\gamma$ (IFN- $\gamma$ ), New Biomarkers, Interleukin-2 (IL-2)

\section{Introduction}

Interferon- $\gamma$ release assays (IGRAs) have been introduced into clinical practice for the diagnosis of MTB (Mycobacterium tuberculosis) infection and current evidence suggests that these two tests measure the interferon- $\gamma$

${ }^{*}$ Corresponding author.

How to cite this paper: Kobash, Y., Mouri, K., Kato, S. and Oka, M. (2015) Clinical Evaluation of New Biomarkers including IFN- $\gamma$ for the Diagnosis of Active Tuberculosis Disease. Journal of Tuberculosis Research, 3, 136-148. 
(IFN- $\gamma$ ) release of activated T cells isolated from the patient's peripheral blood: QuantiFERON-TB Gold InTube (QFT) as an enzyme-linked immunosorbent assay (ELISA) and T-SPOT.TB as an enzyme-linked immunospot assay (ELISPOT). However, previous reports suggest that patients with advanced HIV and a severe immunosuppressive state have an increased proportion of negative and/or indeterminate results [1] [2]. The detection rate of IGRAs can be enhanced by measuring alternative or additional biomarkers for IFN- $\gamma$ [3]-[9]. Especially, it was reported that multiple chemokines such as IFN- $\gamma$-induced protein 10 (IP-10), monokine induced by IFN- $\gamma$ (MIG), monocyte chemotactic protein-1 (MCP-1) and macrophage inflammatory protein (MIP)- $1 \beta$ were strongly induced by MTB-specific antigen stimulation and release showed a high degree of correlation to IFN- $\gamma$ in previous reports [10]-[13]. However, there are few reports about the clinical usefulness of other cytokines or chemokines except IGRAs for the diagnosis of active TB disease in Japan as far as we know.

Therefore, we clinically evaluated several new biomarkers as follows; cytokines (interleukin-2 (IL-2), tumor necrosis factor- $\alpha$ (TNF- $\alpha$ )) and chemokines (MCP-1, MIP-1 $\beta$ ) to confirm which biomarker was most useful for the diagnosis of active TB disease using a supernatant from whole blood stimulated with MTB-specific antigens compared with IFN- $\gamma$ (QFT) through this study in Japan.

\section{Materials and Methods}

\subsection{Study Subjects}

Ninety-three patients were enrolled between 2012 and 2015 and they were diagnosed at Kawasaki Medical School Hospital (1070 beds). Thirty-one patients with active TB disease satisfied smear and/or culture-positive results or PCR-positive for MTB from any clinical specimens. They consisted of 16 with pulmonary TB, 4 with miliary TB, 3 with TB lymphadenopathy, 3 with pulmonary TB + TB pleuritis, 2 with TB pleuritis, 1 with pulmonary TB + bronchial TB, 1 with pulmonary TB+TB lymphadenopathy, 1 with cerebral TB + TB lymphadenopathy. Forty-two patients with NTM disease satisfied the diagnostic criteria proposed by the American Thoracic Society (ATS) [14]. The causative microorganisms consisted of Mycobacterium avium in 20, M. intracellulare in 16, M. kansasii in 3, M. abscessus in 2, and M. avium + M. intraellulare in 1, respectively. Twenty patients with other respiratory diseases were confirmed in terms of histological diagnosis from the specimens using bronchoscopy. The final diagnosis consisted of 5 with lung cancer, 3 with pulmonary abscess, 3 with sinobronchitis syndrome, 3 with pulmonary mycosis, 2 with bronchiectasis, 2 with pulmonary nocardia, 1 with sarcoidosis and 1 with pneumoconiosis, respectively. Concerning the patients with NTM disease or other respiratory diseases, they all required the differentiation from TB disease. However, we included a few patients with a past history of TB disease or pulmonary $M$. kansasii disease which were possible to show false-positive response for new biomarkers including IFN- $\gamma$ inorder to investigate the results of new biomarkers for these patients in this study.

This study was approved by the Ethical committee of Kawasaki Medical School and informed consent was obtained from all participants of this study.

\subsection{IFN- $\gamma$ (QuantiFERON TB Gold In-Tube: QFT)}

A heparinized blood sample was collected from each patient by vein puncture and aliquots were used for QFT tests (IFN- $\gamma$ ), IL-2, TNF- $\alpha$, MCP-1 and MIP- $1 \beta$. QFT (IFN- $\gamma$ ) was performed according to the recommendations of the manufacturer (Cellestis Ltd., Carnegie, Australia). The judgment was performed according to the guideline proposed by the centers for Control and prevention (CDC) for using QFT [15].

\subsection{IL-2, TNF- $\alpha$, MCP- 1 and MIP- $1 \beta$ Assays}

The levels of IL-2-TNF- $\alpha$, MCP-1and MIP-1 $\beta$ were measured using the supernatant acquired from the QFT assay which was stimulated with saline, mitogen or TB-specific antigens (ESAT-6, CFP-10 and TB 7.7). An ELISA Development kit (R\&D Systems Inc, MN, USA) was used to detect IP-10 release and MIG release according to the manufacturer's instructions.

\subsection{Statistical Analysis}

The Mann-Whitney U test was carried out to calculate the differences between individual groups (for example; the TB disease group and NTM disease group, the TB disease group and other disease group and NTM disease 
group and other disease group) and group medians ( $>2)$ were compared using the ANOVA test. The concordance rate test was assessed using the kappa $(\kappa)$ statistic. The diagnostic accuracies of the test of IL-2, TNF- $\alpha$, MCP-1and MIP-1 $\beta$ were evaluated using a receiving operating characteristic (ROC) curve. The ROC analysis was performed according to the literature [16] [17]. The cut-off value was estimated at various sensitivities and specificities and determined at the maximum sensitivity +1 -specificity. A p-value of $<0.05$ was considered significant. Data were analyzed using the Stat Flex version 6 software (Artec, Japan, 2013).

\section{Results}

A total of 93 patients were enrolled during the study period. They consisted of 31 patients with active TB disease (TB group), 42 with NTM disease (NTM group) and 20 with other respiratory diseases (Other disease group). The clinical characteristics of the patients in the three groups are shown in Table 1. There were significant differences in terms of age, sex and underlying disease in the NTM group compared to other groups ( $<$ < 0.05). On the other hand, the patients in the TB group showed significant lymphocytopenia, hypoproteinemia and hypoalbuminemia in the laboratory findings compared to those of other groups $(\mathrm{p}<0.05)$.

The median levels of IFN- $\gamma$ stimulated by MTB-specific antigen (ESAT-6, CFP-10, TB 7.7) were as follows (median \pm S.D); $2.0 \pm 3.4 \mathrm{IU} / \mathrm{ml}$ in the TB group, $0 \pm 1.9 \mathrm{IU} / \mathrm{ml}$ in the NTM group and $0 \pm 2.3 \mathrm{IU} / \mathrm{ml}$ in the other disease group. They were significantly higher in the TB group than the other two groups $(\mathrm{p}<0.001$, Figure 1$)$.

In the judgment of IFN- $\gamma$ (QFT), 23 of 31 patients in the TB group showed a positive response (74\%). In the patients with non-TB disease (the NTM group and other respiratory disease group), the positive response rate was $11 \%$ (7/62) (7\% (3/42) in the NTM group and 25\% (5/20) in the other disease group). One of four patients with healed TB and one of three patients with pulmonary $M$. kansasii disease showed a positive response of IFN- $\gamma$ in the NTM group. One patient with healed TB showed a positive response of IFN- $\gamma$ in the other disease group. On the other hand, two patients in the TB group (7\%) and one patient in the NTM group showed indeterminate responses due to a low mitogen response (Table 2).

Table 1. Clinical characteristics of the three disease groups.

\begin{tabular}{|c|c|c|c|}
\hline & TB group $(n=31)$ & NTM group $(\mathrm{N}=42)$ & Other disease group $(\mathrm{N}=20)$ \\
\hline Age (median \pm S.D.) & $75.0 \pm 21.4$ & $69.5 \pm 13.6^{*}$ & $74.0 \pm 14.1$ \\
\hline Sex (male: female) & $17: 14$ & $16: 26^{*}$ & $12: 8$ \\
\hline Smoking history (+) & $18(58 \%)$ & $14(33 \%)^{*}$ & $9(45 \%)$ \\
\hline Underlying disease $(+)$ & $24(77 \%)$ & $25(60 \%)^{*}$ & 18 (90\%) \\
\hline Respiratory disease $(+)$ & $6(19 \%)$ & 7 (17\%) & $4(20 \%)$ \\
\hline Healed tuberculosis & 2 & 4 & 1 \\
\hline COPD & 1 & 1 & 2 \\
\hline Others & 3 & 2 & 1 \\
\hline Non-respiratory disease $(+)$ & $18(58 \%)$ & $18(43 \%)$ & $14(70 \%)$ \\
\hline Malignant disease & 4 & 4 & 2 \\
\hline Diabetes mellitus & 2 & 3 & 3 \\
\hline Cardiovascular disease & 4 & 3 & 3 \\
\hline Others & 8 & 8 & 6 \\
\hline Immunosuppressive treatment & $3(10 \%)$ & $4(10 \%)$ & $2(10 \%)$ \\
\hline \multicolumn{4}{|c|}{ Laboratory findings (median \pm S.D.) } \\
\hline Lymphocyte $(/ \mu l)$ & $1084 \pm 743^{*}$ & $1435 \pm 651$ & $1525 \pm 594$ \\
\hline Total protein (g/dl) & $6.8 \pm 0.8^{*}$ & $7.3 \pm 0.5$ & $7.1 \pm 0.5$ \\
\hline Albumin (g/dl) & $3.3 \pm 0.8^{*}$ & $4.0 \pm 0.5$ & $3.8 \pm 0.5$ \\
\hline
\end{tabular}

TB: Tuberculosis, NTM: Nontuberculous mycobacteria. COPD: Chronic obstructive pulmonary disease. ${ }^{*} \mathrm{p}<0.05$. 


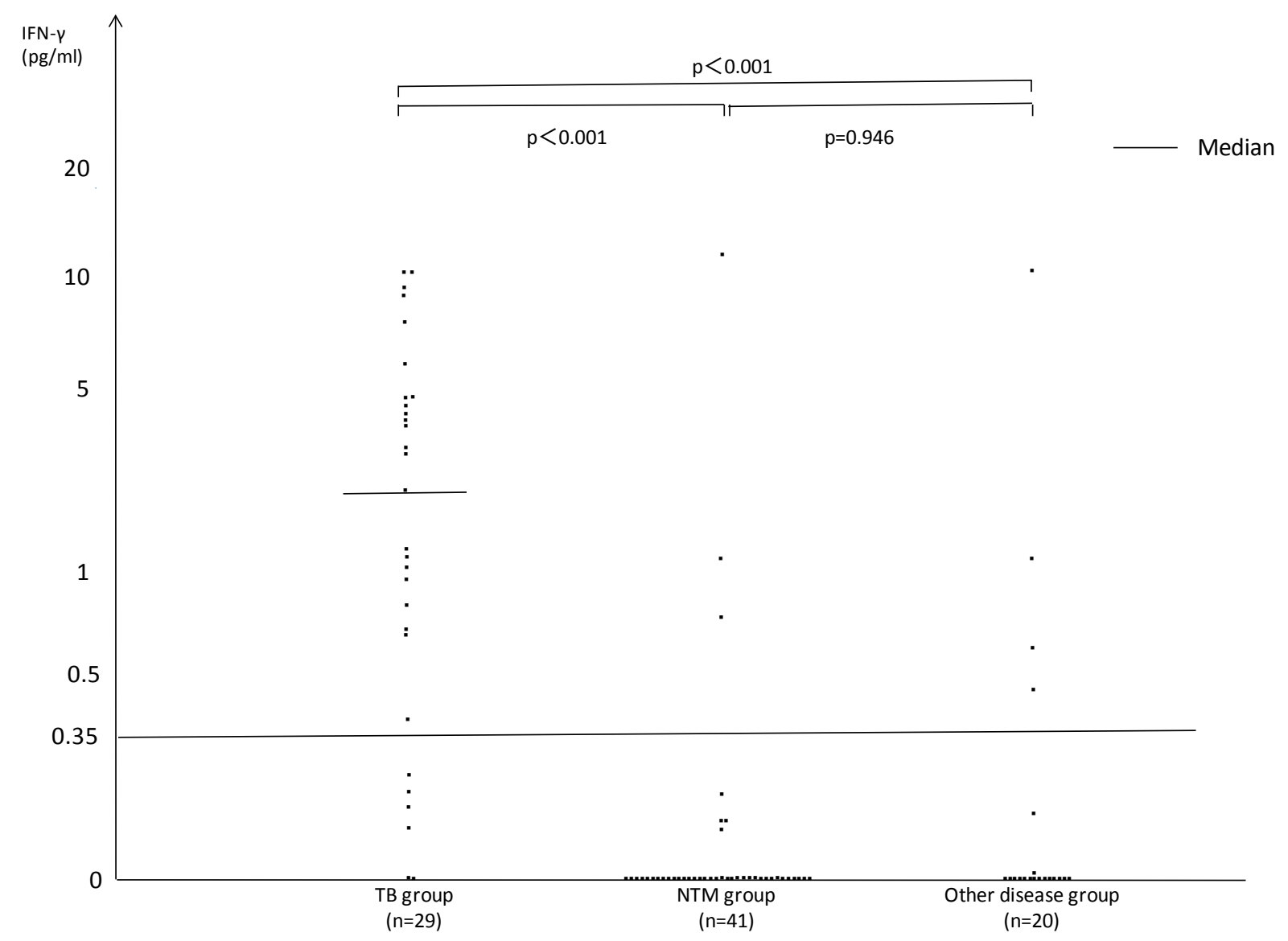

Figure 1. IFN- $\gamma$ concentration for three disease groups excluding patients showed indeterminate results (after stimulation with a TB-specific antigen-negative control).

Table 2. Comparison of the results of IFN- $\gamma$ (QFT), IL-2, TNF- $\alpha$, MCP-1, MIP-1 $\beta$, MIP- $\beta 1$ for patients with TB disease and non-TB disease.

\begin{tabular}{|c|c|c|c|c|c|}
\hline Diagnostic method & Judgment & TB disease $(n=31)$ & Non-TB disease $(n=62)$ & NTM disease $(\mathrm{n}=42)$ & $\begin{array}{l}\text { Other respiratory } \\
\text { disease }(\mathrm{n}=20)\end{array}$ \\
\hline \multirow{3}{*}{ IFN- $\gamma(\mathrm{QFT})$} & Positive & $23(74 \%)$ & $7(11 \%)$ & $3(7 \%)$ & $4(20 \%)$ \\
\hline & Negative & $6(19 \%)$ & 54 (87\%) & 38 (91\%) & $16(80 \%)$ \\
\hline & Indeterminate & $2(7 \%)$ & $1(2 \%)$ & $1(2 \%)$ & 0 \\
\hline \multirow{2}{*}{ IL-2 } & Positive & $19(61 \%)$ & 20 (32\%) & 15 (36\%) & $5(25 \%)$ \\
\hline & Negative & $12(39 \%)$ & $42(68 \%)$ & $27(64 \%)$ & $15(75 \%)$ \\
\hline \multirow{2}{*}{ TNF- $\alpha$} & Positive & $22(71 \%)$ & $16(26 \%)$ & $11(26 \%)$ & 5 (25\%) \\
\hline & Negative & $9(29 \%)$ & $46(74 \%)$ & $31(74 \%)$ & 15 (75\%) \\
\hline \multirow{2}{*}{ MCP-1 } & Positive & 25 (81\%) & $14(23 \%)$ & $9(21 \%)$ & $5(25 \%)$ \\
\hline & Negative & $6(19 \%)$ & 48 (76\%) & 33 (79\%) & 15 (75\%) \\
\hline \multirow{2}{*}{ MIP- $1 \beta$} & Positive & $25(81 \%)$ & $12(19 \%)$ & 7 (17\%) & $5(25 \%)$ \\
\hline & Negative & 6 (19\%) & 50 (81\%) & 35 (83\%) & 15 (75\%) \\
\hline
\end{tabular}

INF- $\gamma$ : Interferon-gamma, QFT: QuantiFERON, I L-2: Interlenkin-2, TNF- $\alpha$ : Tumor necrosis factor- $\alpha$. MCP-1: Monocyte chemotactic Protein1, MIP-1 $\beta$ : Macrophage inflammatory protein-1 $\beta$. 
The median levels of IL-2 stimulated by MTB-specific antigen were as follows (median \pm S.D); $60 \pm 208$ $\mathrm{pg} / \mathrm{ml}$ in the TB group, $20 \pm 89 \mathrm{pg} / \mathrm{ml}$ in the NTM group and $15 \pm 125 \mathrm{pg} / \mathrm{ml}$ in the other disease group. They were significantly higher $(\mathrm{p}<0.001)$ in the patients in the TB group than in those of the other two groups (Figure 2).

The diagnostic performance of IL-2 in the experiment stimulated by the MTB-specific antigen was first assessed with the ROC curve (Figure 3). The patients in the TB group were used as the true positives and non-TB patients consisting of patients with NTM disease and other respiratory diseases were the true negatives. The AUC of IL-2 was 0.682 (95\% CI: 0.623 - 0.740). The optimal cut-off value for IL-2 was determined to be 25 $\mathrm{pg} / \mathrm{ml}$ by the ROC analysis. When the levels stimulated by MTB-specific antigen-negative control levels were estimated over the optical cut-off values, these patients were regarded as having a positive response, and when they were estimated below the cut-off values, they were regarded as having a negative response. While the positive response rate of IL-2 was 61\% (19/31) in the TB group, it was 32\% (20/62) in the non-TB group (36\% (15/42) in the NTM group and 25\% (5/20) in the other respiratory disease group). The positive response rate of IL-2 was significantly higher in the patients in the TB group than in those of the other two groups $(\mathrm{p}<0.001)$ (Table 2). Two of four patients with healed TB and one of three patients with pulmonary M. kansasii disease showed a positive IL-2 response in the NTM group. One patient with healed TB showed a positive IL-2 response in the other disease group.

The median levels of TNF- $\alpha$ stimulated by MTB-specific antigen were as follows (median \pm S.D); $100.0 \pm$ $96.3 \mathrm{pg} / \mathrm{ml}$ in the TB group, $26.0 \pm 55.2 \mathrm{pg} / \mathrm{ml}$ in the NTM group and $32.5 \pm 58.8 \mathrm{pg} / \mathrm{ml}$ in the other respiratory disease group, respectively. They were significantly higher $(\mathrm{p}<0.001)$ in the patients of the TB group than in those of the other two groups (Figure 4).

The diagnostic performance of TNF- $\alpha$ in the experiment stimulated by MTB-specific antigen was assessed with the ROC curve (Figure 5). The AUC of TNF- $\alpha$ was 0.748 (95\% CI: 0.693 - 0.804). The optimal cut-off value for TNF- $\alpha$ was determined to be $38 \mathrm{pg} / \mathrm{ml}$ by the ROC analysis. While the positive response rate of TNF$\alpha$ was $71 \%$ (22/31) in the TB group, it was 26\% (16/62) in the non-TB group (26\% (11/42) in the NTM group and $25 \%(5 / 20)$ in the other disease group). The positive response rate of TNF- $\alpha$ was significantly higher

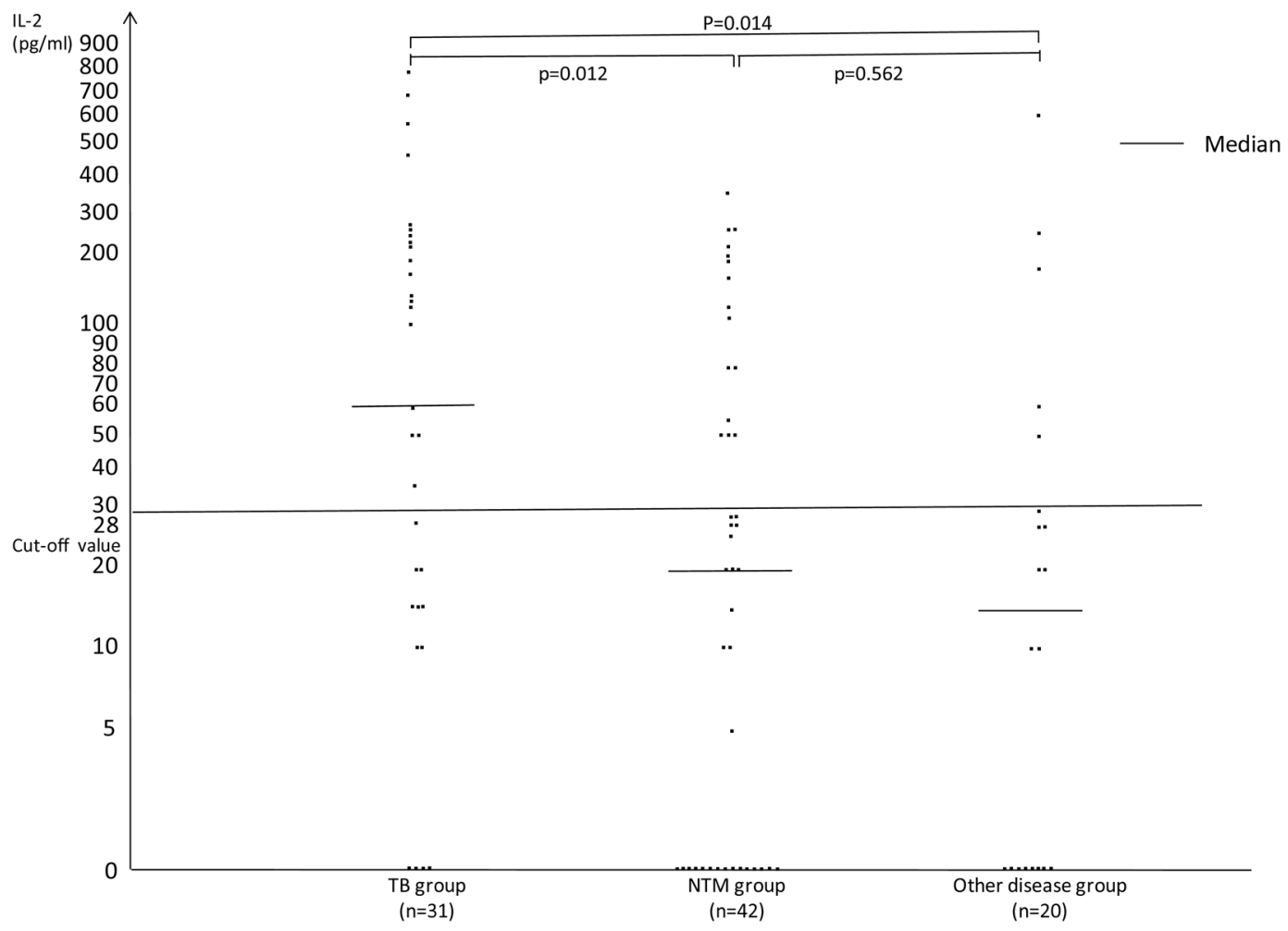

Figure 2. Clinical evaluation of IL-2 for the three disease groups (after stimulation of TB-specific antigennegative control). 


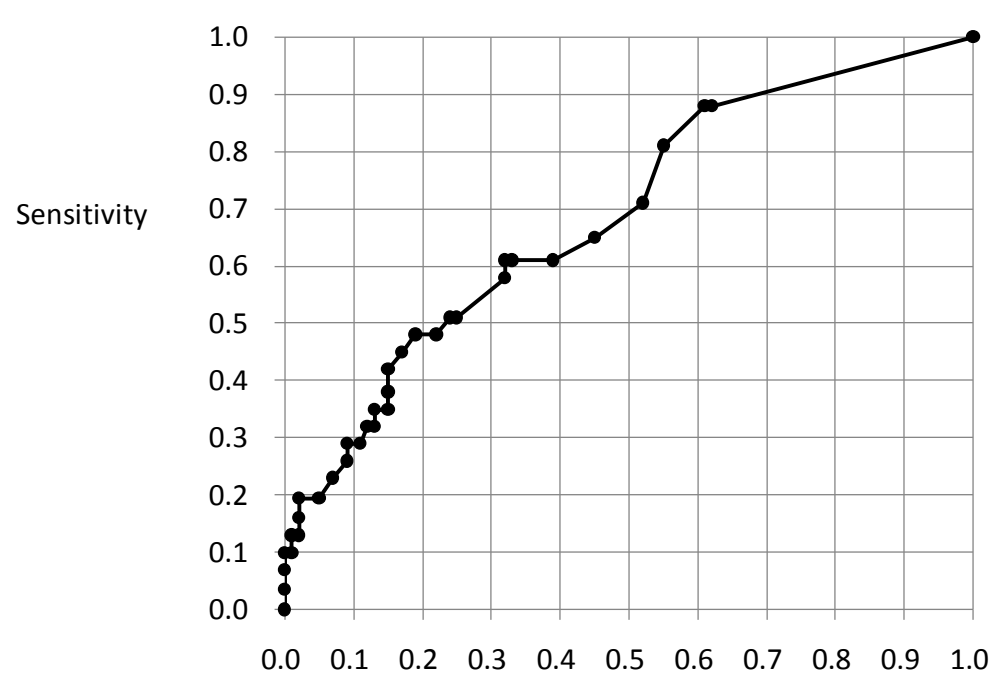

1-Specificity

Figure 3. ROC curve of IL-2 (after stimulation of TB-specific antigen-negative control).

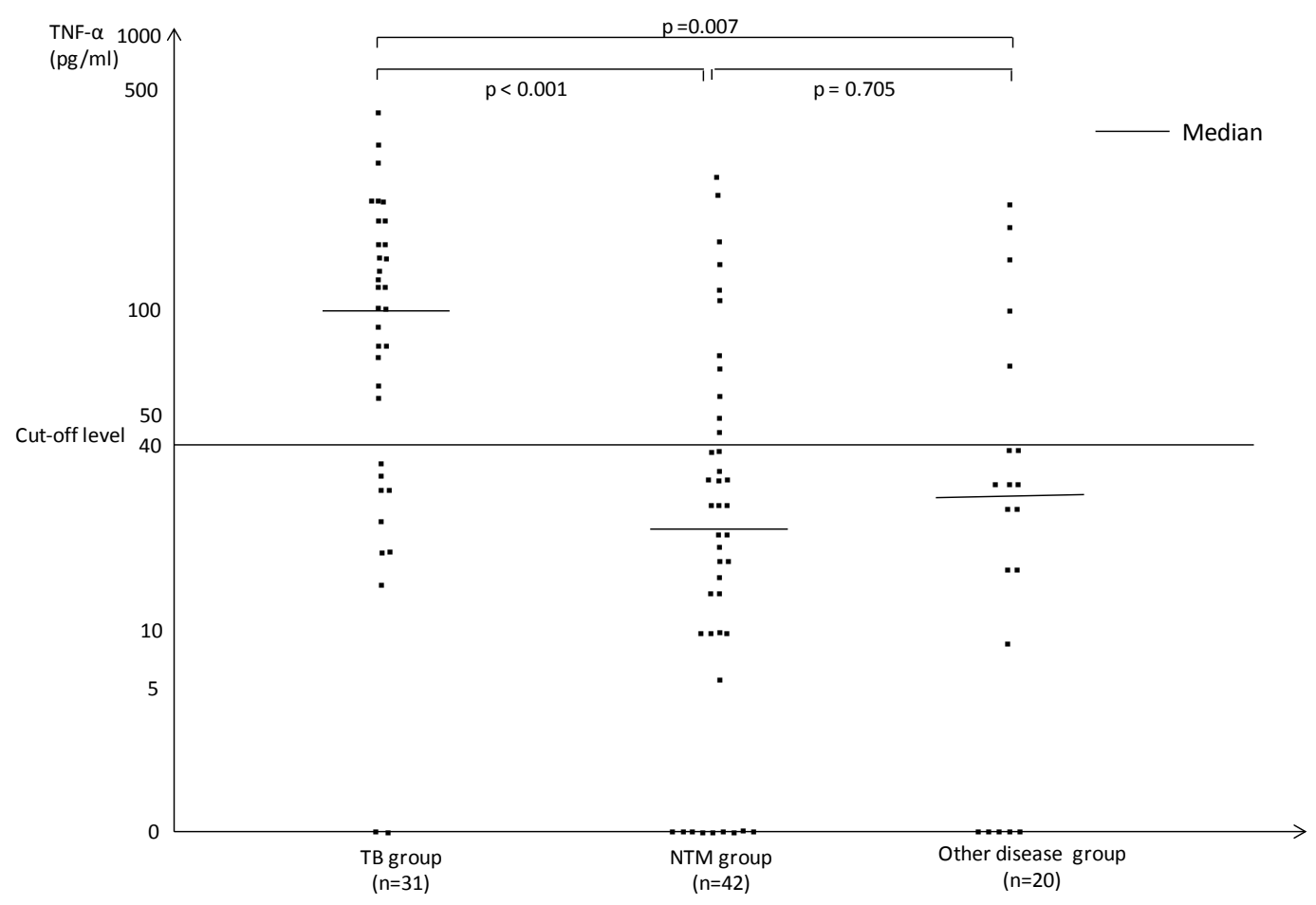

Figure 4. Clinical evaluation of TNF- $\alpha$ for the three disease groups (after stimulation of TB-specific antigennegative control).

in the patients of the TB group than in those of the other two groups ( $p<0.001)$ (Table 2). One of four patients with healed TB and one of three patients with pulmonary M. kansasii disease showed a positive TNF- $\alpha$ response in the NTM group. One patient with healed TB showed a positive TNF- $\alpha$ response of in the other disease group.

The median levels of MCP-1 stimulated by MTB-specific antigen were as follows (median \pm S.D.); $1450 \pm$ $1031 \mathrm{pg} / \mathrm{ml}$ in the TB group, $500 \pm 508 \mathrm{pg} / \mathrm{ml}$ in the NTM group and $325 \pm 541 \mathrm{pg} / \mathrm{ml}$ in the other disease group. They were significantly higher $(\mathrm{p}<0.001)$ in the patients of the TB group than in those of the two other two groups (Figure 6). 


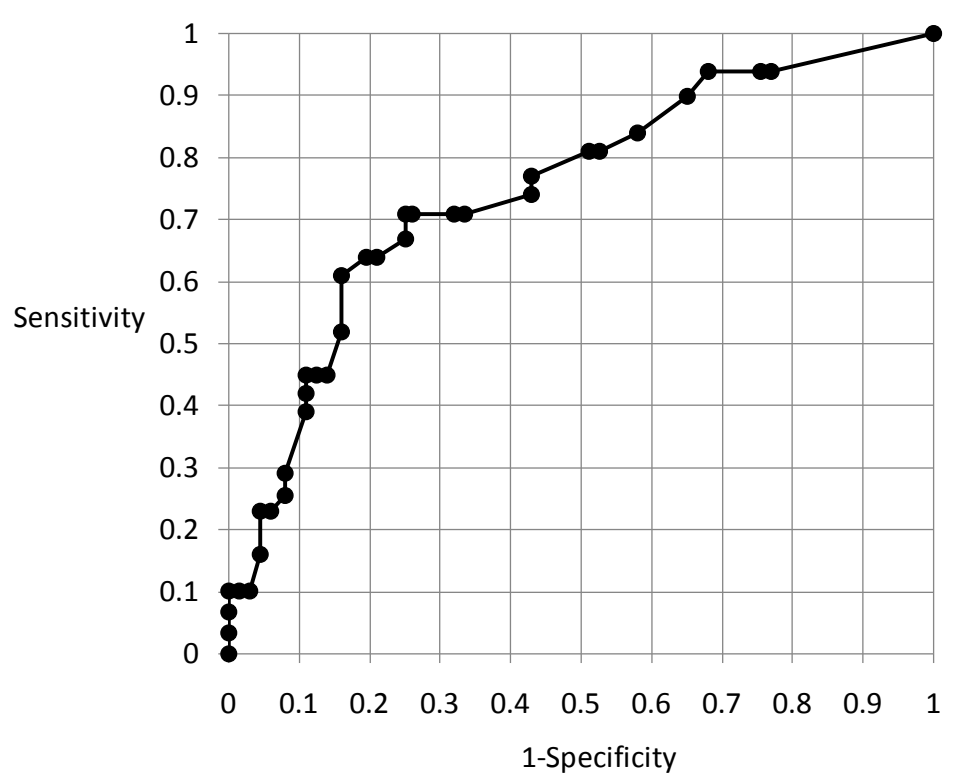

Figure 5. ROC curve of TNF- $\alpha$ (after stimulation of TB-specific antigen-negative control).

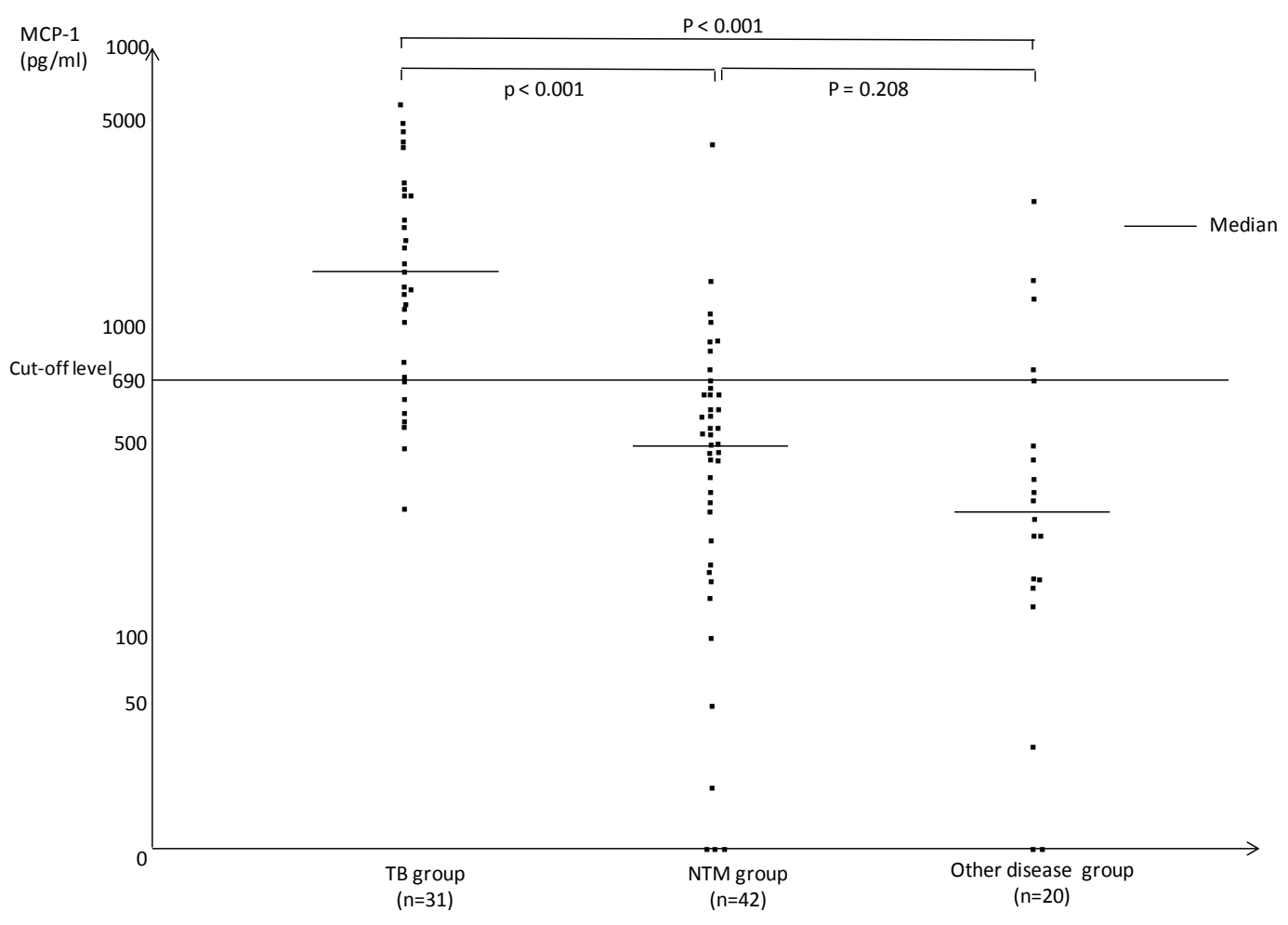

Figure 6. Clinical evaluation of MCP-1 for the three disease groups (after stimulation of TB-specific antigennegative control).

The diagnostic performance of MCP-1 in the experiment stimulated by MTB-specific antigen was assessed with the ROC curve (Figure 7). The AUC of MCP-1 was 0.883 (95\% CI: 0.847 - 0.919). The optimal cut-off value for MCP-1 was determined to be $690 \mathrm{pg} / \mathrm{ml}$ by the ROC analysis. While the positive response rate of MCP-1 was $81 \%$ (25/31) in the TB group, it was 23\% (14/42) in the non-TB group (21\% (11/42) in the NTM group and $25 \%$ (5/20) in the other disease group). The positive response rate of MCP-1 was significantly higher $(\mathrm{p}<0.001)$ in the patients in the TB group than in those in the other two groups (Table 2). One of four patients 


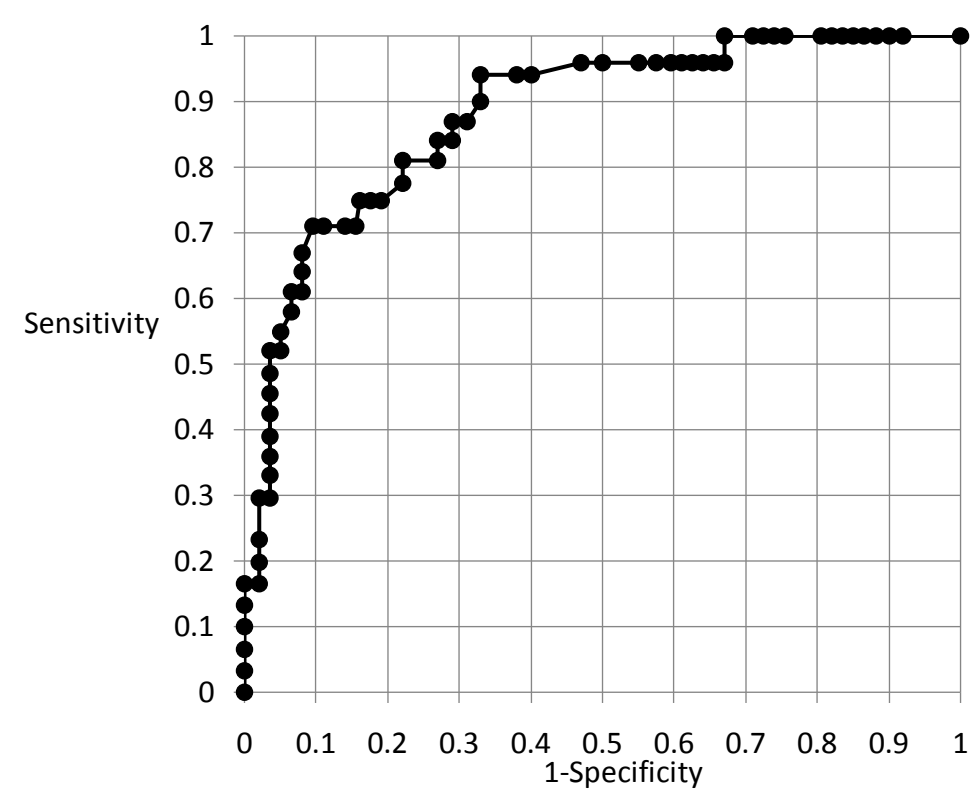

Figure 7. ROC curve of MCP-1 (after stimulation of TB-specific antigen-negative control).

with healed TB and one of three patients with pulmonary $M$. kansasii disease showed a positive response of MCP-1 in the NTM group. One patient with healed TB showed a positive response of MCP-1 in the other disease group.

The median levels of MIP- $1 \beta$ stimulated by MTB-specific antigen were as follows (median \pm S.D.); $4240 \pm$ $3041 \mathrm{pg} / \mathrm{ml}$ in the TB group, $1400 \pm 1669 \mathrm{pg} / \mathrm{ml}$ in the NTM group and $770 \pm 2378 \mathrm{pg} / \mathrm{ml}$ in the other disease group. They were significantly higher $(\mathrm{p}<0.001)$ in the patients of the TB group than in those of the other two groups (Figure 8).

The diagnostic performance of MIP- $1 \beta$ in the experiment stimulated by the MTB-specificantigen was assessed with ROC curve (Figure 9). The AUC of MIP-1 $\beta$ was 0.777 (95\% CI: 0.721 - 0.833). The optimal cutoff value for MIP- $1 \beta$ was determined to be $1975 \mathrm{pg} / \mathrm{ml}$ by the ROC analysis. While the positive response rate of MIP- $1 \beta$ was $81 \%(25 / 31)$ in the TB group, it was $19 \%(12 / 62)$ in the non-TB group $(17 \%(7 / 42)$ in the NTM group and $25 \%(5 / 20)$ in the other disease group). The positive response rate of MIP- $1 \beta$ was significantly higher $(\mathrm{p}<0.001)$ in the patients in the TB group than in those in the other two groups (Table 2). One of four patients with healed TB and one of three patients with pulmonary $M$. kansasii disease showed a positive MIP- $1 \beta$ response in the NTM group. One patient with healed TB showed a positive MIP- $1 \beta$ response in the other disease group.

In 31 patients tested in the TB group, IFN- $\gamma$, IL-2, TNF- $\alpha$, MCP- 1 and MIP- $1 \beta$ showed sensitivities of $74.0 \%$ (95\% CI: 69.7\% - 78.3\%), 61.3\% (95\% CI: 57.0\% - 65.7\%), 71.0\% (95\% CI: 66.5\% - 75.5\%), and 77.4\% (95\% CI: $73.0 \%-81.8 \%), 80.6 \%$ (95\% CI: 76.2\% - 84.8\%) respectively. When the indeterminate results were excluded for sensitivity calculations, IFN- $\gamma$ yielded diagnostic sensitivities of 79.3\% (95\% CI: 74.9\% - 83.8\%). Although there were no significant differences among the five tests, the sensitivity of IL-2 was the lowest for the differential diagnosis of TB disease. In 62 patients tested in the non-TB group, IFN- $\gamma$, IL-2, TNF- $\alpha$, MCP-1 and MIP-1 $\beta$ showed specificities of 87.0\% (95\% CI: 82.5\% - 91.5\%), 67.0\% (95\% CI: 62.6\% - 71.4\%), 74.2\% (95\% CI: $69.9 \%$ - 78.5\%), 78.5\% (95\% CI: 74.2\% - 82.8\%) and 79.0\% (95\% CI: 74.6\% - 83.4\%), respectively. Although there were no significant differences among the four tests in terms of specificity, the specificity of IL-2 was the lowest for the differential diagnosis of TB disease as well as sensitivity. On the other hand, the positive predictive values (PPV) for IFN- $\gamma$, IL-2, TNF- $\alpha$, MCP-1 and MIP- $1 \beta$ were $76.7 \%$ (95\% CI: $72.8 \%$ - 80.6\%), $44.2 \%$ (95\% CI: $40.1 \%$ - 48.3\%), 57.9\% (95\% CI: 53.9\% - 62.0\%), 63.4\% (95\% CI: 59.3\% - 67.5\%), 67.6\% (95\% CI: $63.8 \%-71.5 \%$ ). The negative predictive values (NPV) for IFN- $\gamma$, IL-2, TNF- $\alpha$, MCP-1 and MIP- $1 \beta$ were 90.0\% (95\% CI: 86.0\% - 94.0\%), 76.7\% (95\% CI: 72.8\% - 80.6\%), 83.5\% (95\% CI: 79.6\% - 87.4\%), 87.8\% (95\% CI: 83.9\% - 91.7\%), 89.3\% (95\% CI: 85.2\% - 93.4\%), respectively.

Concerning the concordance between IFN- $\gamma$ and IL-2, TNF- $\alpha$, MCP-1 or MIP- $1 \beta$ combined patients with TB 


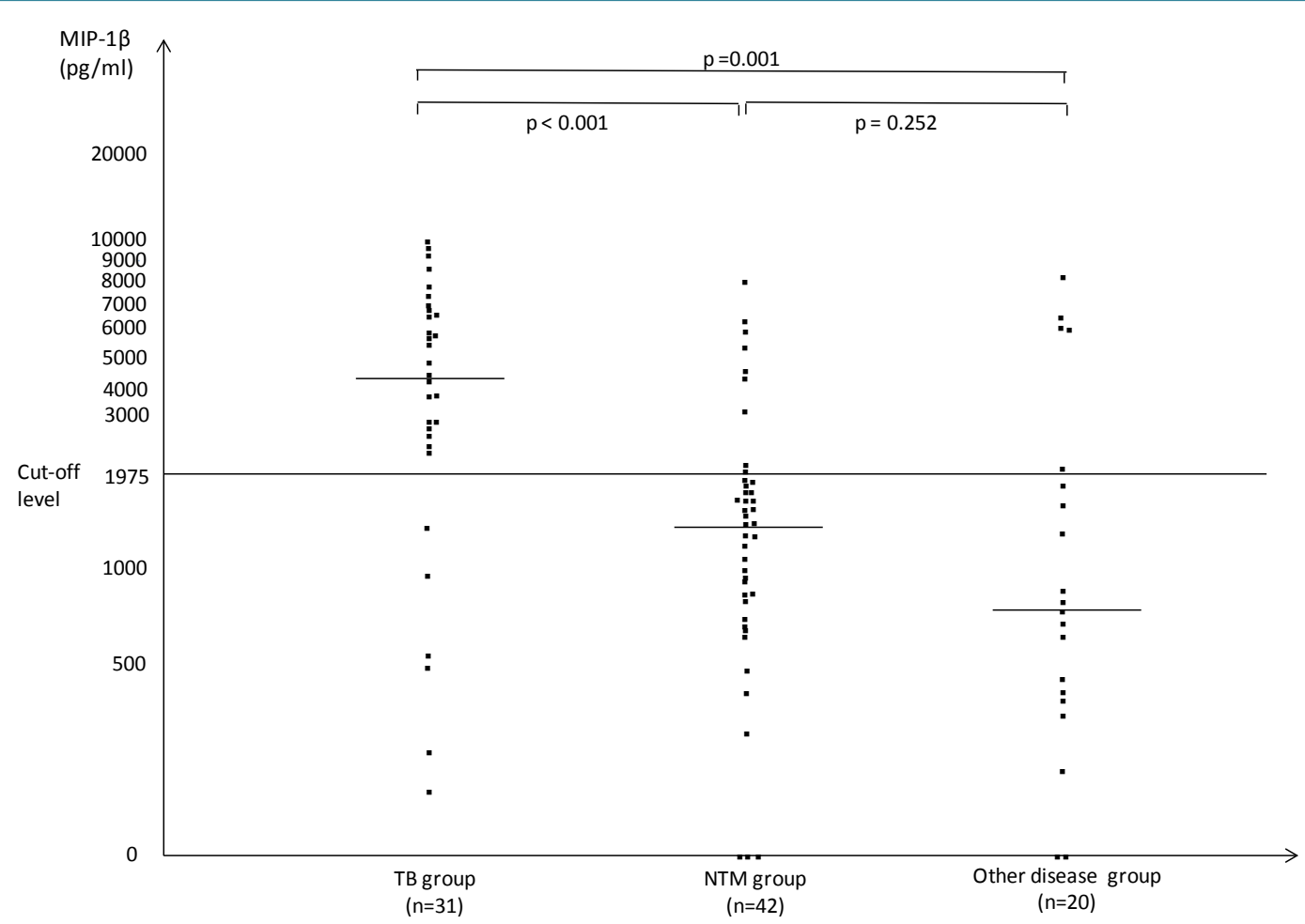

Figure 8. ROC curve of MCP-1 (after stimulation of TB-specific antigen-negative control).

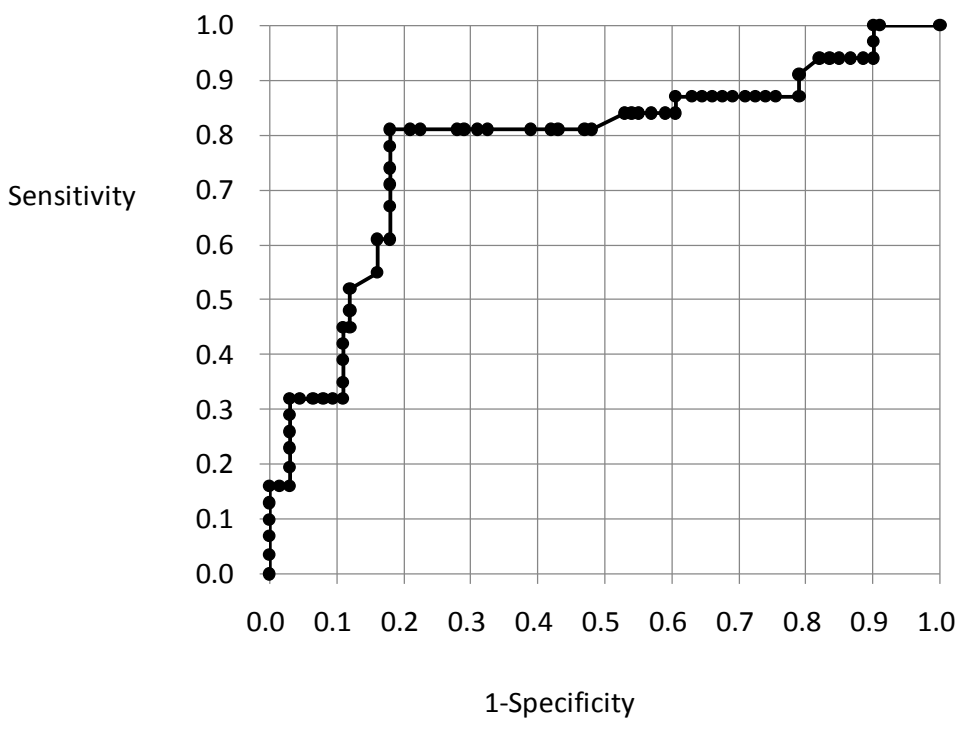

Figure 9. ROC curve of MIP-1 $\beta$ (after stimulation of TB-specific antigen-negative control).

disease and non-TB disease, the concordance rate of IFN- $\gamma$ and IL-2 was 76.3\% $(\kappa=0.542)$, that of IFN- $\gamma$ and TNF- $\alpha$ was $79.6 \%(\kappa=0.662)$, that of IFN- $\gamma$ and MCP- 1 was $84.9 \%(\kappa=0.745)$ and that of IFN- $\gamma$ and MIP- $1 \beta$ was $82.8 \%(\kappa=0.688)$. The concordance rate of the fivetests in patients with TB disease was $54.8 \%(17 / 31)$. Using the five tests, a positive response was found in 30 of 31 patients with TB disease (96.8\%). In total, the five tests agreed in 52 out of 93 patients (55.9\%) and there was moderate agreement.

\section{Discussion}

In recent reports about biomarkers for immunodiagnosis of infection with MTB [18], it was mentioned that IL-2, 
TNF- $\alpha$, MCP-1 or MIP-1 $\beta$, as well as IP-10 or MIG, had $>10$ fold strong induction compared to IFN- $\gamma$. Therefore, we explored which alternative cytokine and chemokines are consistently and specifically expressed in response to MTB-specific antigens stimulation in whole blood from patients with active TB disease in this study. Subsequently, while MCP-1 and MIP- $1 \beta$ were useful biomarkers to make a differential diagnosis of TB disease and non-TB disease or obtain a diagnosis of active TB disease, IL-2 showed the poorest results. Concerning the comparison with IFN- $\gamma$ (QFT), although the results of MCP-1 and MIP- $1 \beta$ were similar to those of INF- $\gamma$ in terms of sensitivity and specificity, those of IL-2 and TNF- $\alpha$, and especially IL-2, were inferior to those of IFN- $\gamma$.

IL-2 is mainly produced by activated T-cell. The binding to the T-cell receptor stimulates IL-2 secretion and the expression of IL-2 receptor. Finally, the IL-2 receptor ligation activates effector T-cells and the establishment of T-cell memory. Millington et al. and Wang et al. have described that IL-2 has comparable sensitivity and specificity for active TB as well as IFN- $\gamma$ and IP-10 [19] [20]. However, other recent studies suggest that IL-2 expression is lower in patients with active TB disease compared to latent TB infection (LTBI) and controls [21] [22]. LTBI and infection control are dominated by central memory T-cells with potential IL-2 and optionally IFN- $\gamma$ co-secretion; where as active TB disease is characterized by loss of IL-2 production and T-cells with effector memory T-cell phenotype [23]-[27]. Mamishi et al. also described that IL-2 release stimulated by TBspecific antigens was significantly higher in individuals with LTBI compared to patients with active TB disease; therefore, IL-2 could be a potential biomarker for discriminating between active and latent TB infection [28] [29]. On the other hand, concerning the position of TNF- $\alpha$ for IFN- $\gamma$ and IL-2, Harari et al. evaluated CD4 T-cells producing IFN- $\gamma$, TNF- $\alpha$ and IL-2 by flow cytometry in patients with active TB disease and LTBI. As a result, the proportion of MTB-specific CD4+ TNF- $\alpha$ single -positive T-cells was predominantly found in patients with active TB disease and that of polyfunctional MTB-specific CD4+T-cells producing TNF- $\alpha$, IL-2 and IFN- $\gamma$ was dominant in those with LTBI [7]. Petruccioli et al. also described that bifunctional IFN- $\gamma /$ TNF- $\alpha$ specific cells and the effector memory phenotype were significantly associated with active TB disease compared to LTBI or cured TB [27]. Although the reason for the lowest sensitivity and specificity of IL-2 compared to IFN- $\gamma$ in this study may be explained by these previous reports, the lower sensitivity and specificity of TNF- $\alpha$ compared to IFN- $\gamma$ was not compatible.

MCP-1 is released in response of TNF- $\alpha$ and IL-1 stimulation of antigen-presenting cells.MCP-1 expression is variable and has been associated with severity of TB disease [30]. Previous case-control studies suggest that MCP-1 is secreted in response to antigen stimulation in patients with active TB disease, but not in healthy controls [31] [32]. Frahm et al. and Rubbo et al. suggested that MCP-1 had a differential diagnostic potential in combination with IGRAs [11] [33]. The clinical potential of MCP-1 was similar to that of IFN- $\gamma$ (the sensitivity of MCP-1: $77.4 \%$ versus IFN- $\gamma:$ : 74.0\% and the specificity of MCP-1: $78.5 \%$ versus IFN- $\gamma:$ : $7.0 \%$ ) in this study. If a combined diagnostic method of IFN- $\gamma$ and MCP-1 were developed, the diagnostic accuracy may be increased.

MIP- $1 \beta$ is produced by activated macrophages and T-cells and inducible by TNF- $\alpha$, IFN- $\gamma$ and IL- 1 [34]. Chegou et al. evaluated the potential of MIP- $1 \beta$ in a supernatant stimulated by MTB-specific antigens of patients with active TB disease and household contacts [13]. The results of MIP- $1 \beta$ ascertained the presence of active TB disease with a sensitivity of $85 \%$ and specificity of $61 \%$. Similar results were also obtained in a lowburden tuberculosis setting and MIP-1 $\beta$ showed excellent sensitivity and specificity [10], but another study showed little potential for MIP- $1 \beta$ in the diagnosis of active TB disease [11]. The results for MIP- $1 \beta$ were similar to those of IFN- $\gamma$ (the sensitivity of MIP-1 $\beta$ : $80.6 \%$ versus IFN- $\gamma: 74.0 \%$ and the specificity of MIP- $1 \beta: 79.0 \%$ versus IFN- $\gamma: 87.0 \%$ ) in this study. Because it was mentioned that MIP- $1 \beta$ showed the most potential when used in combination with other markers [13], it may be better to add MIP-1 $\beta$ to IFN- $\gamma$ when we would like to discriminate active TB disease and other respiratory diseases.

Regarding the agreement between IFN- $\gamma$ and other individual cytokines (IL-2, TNF- $\alpha$ ) or individual chemokines (MCP-1, MIP-1 $\beta$ ) stimulated by MTB-specificantigens, the rate of agreement was highest in the combination of IFN- $\gamma$ and MCP-1 (84.9\%) but lowest in the combination of IFN- $\gamma$ and IL-2 (76.3\%). These results were correlated with the sensitivity and specificity of active TB disease. If we judged positive when any of the two IGRAs, IP-10 and MIG stimulated by MTB specific-antigens showed a positive response, the positive response rate was increased to $96.8 \%$.

Although it has been reported that IFN- $\gamma$ (QFT) has arisk of false-positive results for patients with healed TB or NTM disease (M. kansasii, etc), one of three patients with pulmonary M. kansasii disease and two of five pa- 
tients with healed TB showed false-positive results with other all biomarkers as well as IFN- $\gamma$ in this study. In addition, another patient with healed TB showed a false-positive result for IL-2. This result may be related to the positive response for IL-2 for patients with cured TB. Because we useda supernatant stimulated by MTB-specific antigens in the measurement of all biomarkers, we have to be careful with the judgment of all biomarkers for these patients, as well as IFN- $\gamma$.

There are some limitations to this study. Firstly, although it used a small number of patients with underlying disease in order to evaluate the usefulness of the diagnosis of active TB disease, it was geographically restricted to a small area in Japan with anintermediate TB population. We hope that a large scale nationwide study will be practically performed with immunological tests such as IFN- $\gamma$ (QFT) in combination with other cytokine or chemokine quantification in a hospital setting in Japan. Secondly, although IL-2 showed the lowest sensitivity and specificity for active TB disease in this study, we have to investigate the response of multiple biomarkers, including IL-2, using a supernatant stimulated by MTB-specific antigens for patients with only active TB disease or LTBI, as well as also cured TB or healed TB in near future.

\section{Conclusion}

In conclusion, several biomarkers apart from IL-2 showed similar results compared with IFN- $\gamma$. The combination of IFN- $\gamma$ and other new biomarkers may increase the diagnostic accuracy of active TB.

\section{Acknowledgements}

This study was supported by a grant from MEXT KAKENHI (23591168).

\section{Conflict of Interest}

There is no conflict of interest for any author.

\section{References}

[1] Mandalakas, A.M., Hesseling, A.C., Chegou, N.N., Kirchner, H.L., Zhu, X., Marais, B.J., et al. (2008) High Level of Discordant IGRA Results in HIV-Infected Adults and Children. International Journal Tuberculosis and Lung Disease, 12, 417-423.

[2] Lange, C., Pai, M., Drobniewski, F. and Migliori, B. (2009) Interferon-Gamma Release Assays for the Diagnosis of Active Tuberculosis: Sensible or Silly? European Respiratory Journal, 3, 1250-1253. http://dx.doi.org/10.1183/09031936.00019709

[3] Walzl, G., Roacher, K., Hanekom, W., Scriba, T.J. and Zumla, A. (2011) Immunological Biomarkers of Tuberculosis. Nature Review Immunology, 11, 3443-3454. http://dx.doi.org/10.1038/nri2960

[4] Lindestam, A.C.S., Gerasimova, A., Mele, F., Henderson, R., Swann, J., Greenbaum, J.A., et al. (2013) Memory T Cells in Latent Mycobacterium tuberculosis Infection Are Directed Against Three Antigenic Islands and Largely Contained in a CXCR ${ }^{3+} \mathrm{CCR}^{6+}$ Th1 Subset. PLoS Pathology, 9, e1003130. http://dx.doi.org/10.1371/journal.ppat.1003130

[5] Dorhri, A., Reece, S.T. and Kaufmann, S.H.E. (2011) For Better or for Worse: The Immune Response against Mycobacterium tuberculosis Balances Pathology and Protection. Immunology Review, 240, 235-251. http://dx.doi.org/10.1111/j.1600-065X.2010.00994.x

[6] Ruhwald, M. and Ravn, P. (2009) Biomarkers for Latent TB Infection. Expert Review Respiratory Medicine, 3, 387401. http://dx.doi.org/10.1586/ers.09.31

[7] Harari, A., Rozot, V., Enders, F.B., Perreau, M., Stalder, J.M., Nicod, L.P., Cavassini, M., et al. (2011) Dominant TNF- $\alpha^{+}$Mycobacterium tuberculosis-Specific CD4 ${ }^{+}$T Cell Responses Discriminate between Latent Infection and Active Disease. Nature Medicine, 17, 372-376. http://dx.doi.org/10.1038/nm.2299

[8] Krummel, B., Strassburg, A., Ernst, M., Reiling, N., Eker, B., Rath, H., et al. (2010) Potential Role for IL-2 ELISpot in Differentiating Recent and Remote Infection in Tuberculosis Contact Tracing. PLoS ONE, 5, e22670. http://dx.doi.org/10.1371/journal.pone.0011670

[9] Ruhwald, M., Dominguez, J., Latorre, I., Lasi, M., Richeldi, L., Pasticci, M.B., et al. (2011) A Multicenter Evaluation of the Accuracy and Performance of IP-10 for the Diagnosis of Infection with M. tuberculosis. Tuberculosis (Edinb), 91, 260-267. http://dx.doi.org/10.1016/j.tube.2011.01.001

[10] Kellar, K.L., Gehrke, J., Weis, S.E., Mahmutoric-Mayhew, A., Darila, B., Zajdowicz, M.J., et al. (2011) Multiple Cytokines Are Released When Blood from Patients with Tuberculosis Is Stimulated with Mycobacterium tuberculosis 
Antigens. PLoS ONE, 6, e26545. http://dx.doi.org/10.1371/journal.pone.0026545

[11] Frahm, M., Goswami, N.D., Owzar, K., Hecker, E., Mosher, A., Cadogan, E., et al. (2011) Discriminating between Latent and Active Tuberculosis with Multiple Biomarker Responses. Tuberculosis, 91, 250-256. http://dx.doi.org/10.1016/j.tube.2011.02.006

[12] Borgstrom, E., Andersen, P., Andersson, L., Julander, I., Kallenius, G., Maeurer, M., et al. (2011) Detection of Proliferative Responses to ESAT-6 and CFP-10 by FASCIA Assay for Diagnosis of Mycobacterium tuberculosis Infection. Journal of Immunological Methods, 370, 55-64. http://dx.doi.org/10.1016/j.jim.2011.05.008

[13] Chegou, N., Black, G., Kidd, M., van Helden, P.D., Walze, G., et al. (2009) Host Markers in Quantiferon Supernatants Differentiate Active TB from Latent TB Infection; Preliminary Report. BMC Pulmonary Medicine, 9, 21. http://dx.doi.org/10.1186/1471-2466-9-21

[14] Griffith, D.E., Alsamit, T., Brown-Elliot, B.A., Catanzero, A., Daley, C., Gordin, F., et al. (2007) An Official ATS/ IDSA Statement: Diagnosis, Treatment, and Prevention of Nontuberculous Mycobacteria Diseases. American Journal of Respiratory Critical Care Medicine, 157, 367-416. http://dx.doi.org/10.1164/rccm.200604-571ST

[15] Mazurek, G.H., Jereb, J., Vernon, A., LoBue, P., Goldberg, S., Castro, K., et al. (2010) Updated Guidelines for Suing Interferon Gamma Release Assays to Detect Mycobacterium Tuberculosis Infection-United States. MMWR Recommend Report, 59, 1-25.

[16] Hanley, J.A. and McNeil, B.J. (1982) The Meaning and Use of the Area under a Receiver Operating Characteristics (ROC) Curve. Radiology, 143, 29-36. http://dx.doi.org/10.1148/radiology.143.1.7063747

[17] Zweig, M.H. and Campbell, G. (1993) Receiver Operating Characteristics (ROC) Plots: A Fundamental Evaluation Tool in Clinical Medicine. Clinical Chemistry, 39, 561-577.

[18] Chegou, N.N., Heyckendorf, J., Waltl, G., Lange, C. and Ruhwald, M. (2014) Beyond the IFN- $\gamma$ Horizon: Biomarkers for Immunodiagnosis of Infection with Mycobacterium tuberculosis. European Respiratory Journal, 43, 1472-1486. http://dx.doi.org/10.1183/09031936.00151413

[19] Millington, K.A., Innes, J.A., Hackforth, S., Hinks, T.S., Deeks, J.J., Dosanjh, D.P., et al. (2007) Dynamic Relationship between IFN- $\gamma$ and IL-2 Profile of Mycobacterium tuberculosis-Specific T Cells and Antigen Load. Journal of Immunology, 178, 5217-5226. http://dx.doi.org/10.4049/jimmunol.178.8.5217

[20] Wang, S., Diao, N., Lu, C., Wu, J., Gao, T., Chen, J., et al. (2012) Evaluation of the Diagnostic Potential of IP-10 and IL-2 as Biomarkers for the Diagnosis of Active and Latent Tuberculosis in a BCG-Vaccinated Population. PLoS ONE, 7, e51338. http://dx.doi.org/10.1371/journal.pone.0051338

[21] Borgstrom, E., Andersen, P., Atterfelt, F., Julander, I., Kallenius, G., Maeurer, M., et al. (2012) Immune Responses to ESAT-6 and CFP-10 by FASCIA and Multiplex Technology for Diagnosis of M. tuberculosis Infection; IP-10 Is a Promising Marker. PLoS ONE, 7, e43438. http://dx.doi.org/10.1371/journal.pone.0043438

[22] Biselli, R., Mariotti, S., Sargentini, V., Sauzallo, I., Lastilla, M., Mengoni, F., et al. (2012) Detection of Interleukin-2 in Addition to Interferon- $\gamma$ Discriminate Active Tuberculosis Patients, Latently Infected Individuals, and Controls. Clinical Microbiological Infection, 16, 1282-1284. http://dx.doi.org/10.1111/j.1469-0691.2009.03104.X

[23] Day, C.L., Abrahams, D.A., Lerumo, L., Janse van Rensburg, E., Stone, L., Orie, T., et al. (2011) Functional Capacity of Mycobacterium tuberculosis-Specific T Cell Responses in Human Is Associated with Mycobacterial Load. Journal of Immunology, 187, 2222-2232. http://dx.doi.org/10.4049/jimmunol.1101122

[24] Sester, U., Fousse, M., Dirks, J., Mack, U., Prasse, A., Singh, M., et al. (2011) Whole-Blood Flow-Cytometric Analysis of Antigen-Specific CD4 T-Cell Cytokine Profiles Distinguishes Active Tuberculosis from Non-Active States. PLoS ONE, 6, e17813. http://dx.doi.org/10.1371/journal.pone.0017813

[25] Casey, R., Blumenkrantz, D., Millington, K., Montamat-Sicotte, D., Kon, O.M., Wickremasinghe, M., et al. (2010) Enumeration of Functional T-Cell Subsets by Fluorescence-Immunospot Defines Signatures of Pathogen Burden in Tuberculosis. PLoS ONE, 5, e15619. http://dx.doi.org/10.1371/journal.pone.0015619

[26] Sargentini, V., Mariotti, S., Carrara, S., Gramiccioni, C., Manara, M., Tagliapietra, G., et al. (2009) Cytometric Detection of Antigen-Specific IFN-Gamma/IL-2 Secreting Cells in the Diagnosis of Tuberculosis. BMC Infectious Disease, 9, 99. http://dx.doi.org/10.1186/1471-2334-9-99

[27] Petruccioli, E., Petrone, L., Vanini, V., Sampaolesi, A., Gualono, G., Girardi, E., et al. (2013) IFN- $\gamma /$ TNF- $\alpha$ Specific Cells and Effector Memory Phenotype Associate with Active Tuberculosis. Journal of Infection, 66, 475-486. http://dx.doi.org/10.1016/j.jinf.2013.02.004

[28] Mamishi, S., Pourakbari, B., Teymuri, M., Rubbo, P.A., Tuaillon, E., Keshtkar, A., et al. (2014) Diagnostic Accuracy of IL-2 for the Diagnosis of Latent Tuberculosis: A Systematic Review and Meta-Analysis. European Journal of Clinical Microbiology and Infectious Disease, 33, 2111-2118. http://dx.doi.org/10.1007/s10096-014-2190-z

[29] Mamishi, S., Pourakbari, B., Marjani, M., Bahador, A. and Mahmoudi, S. (2015) Discriminating between Latent and Active Tuberculosis: The Role of Interleukin-2 as Biomarker. Journal of Infection, 70, 429-431. 
http://dx.doi.org/10.1016/j.jinf.2014.12.011

[30] Hasan, Z., Cliff, J.M., Dockrell, H.M., Jamil, B., Irfan, M., Ashraf, M., et al. (2009) CCL2 Responses to Mycobacterium Tuberculosis Are Associated with Disease Severity in Tuberculosis. PLoS ONE, 4, e8459. http://dx.doi.org/10.1371/journal.pone.0008459

[31] Bibova, I., Linhartova, I., Stanek, O., Rusnakova, V., Kubista, M., Suchanek, M., et al. (2012) Detection of Immune Cell Response to M. tuberculosis-Specific Antigens by Quantitative Polymerase Chain Reaction. Diagnostic Microbiology and Infectious Disease, 72, 68-78. http://dx.doi.org/10.1016/j.diagmicrobio.2011.09.024

[32] Ruhwald, M., Bjerregaard-Andersen, M., Rabna, P., Eugen-Olsen, J. and Ravn, P. (2009) IP-10, MCP-1, MCP-2, MCP-3, and IL-1RA Hold Promise as Biomarkers Fir Infection with M. tuberculosis in a Whole Blood Based T-Cell Assay. BMC Research Notes, 2, 19. http://dx.doi.org/10.1186/1756-0500-2-19

[33] Rubbo, P.A., Nagot, Moing, V.L., Brabet, M., Bourdin, A., Nogue, E., et al. (2012) Multi-Cytokine Detection Improves Latent Tuberculosis Diagnosis in Healthcare Workers. Journal of Clinical Microbiology, 50, 1711-1717. http://dx.doi.org/10.1128/JCM.00117-12

[34] Maurer, M. and von Stebut, E. (2004) Macrophage Inflammatory Protein-1. International Journal of Biochemical Cell Biology, 36, 1882-1886. http://dx.doi.org/10.1016/j.biocel.2003.10.019 